children under 5 years, in an attempt to better protect the more compliant nature of the heads of very young children. There is also some concern regarding the fit and stability of children's helmets which have been tested on headforms based on adult anthropometry. Growth of the skull (and changes to head shape) takes place for about seven years after birth. Headforms based on child head shapes are important to promote helmet design of good fit and stability for infants and toddlers.

For all these concerns, it should be noted that field studies show that bicycle helmets are most effective in reducing the likelihood of head injuries and helmets remain the single most effective protective system available to cyclists. But bicycle helmets can and should be improved to provide better protection to all cyclists. And one effective way of doing this is to upgrade the performance requirements of helmet standards and for mandatory helmet wearing legislation to reference only those standards which promote better helmet designs for the entire cycling population.

\title{
DISSENT
}

\section{Bicycle helmets reduce head injuries and should be worn by all}

\author{
Peter Vulcan, John Lane
}

Cycling is a pleasant, healthy pastime and a low cost means of transport. Apart from the drawback of being exposed to all kinds of weather, the main disadvantage of bicycling is that in a crash, cyclists often suffer injuries, the most severe of which is usually a head injury. Bicycle helmets have provided the means to prevent many of these head injuries and the challenge facing public health and transport officials around the world is to promote and ultimately, mandate their use.

Much progress has been made in the six years since bicycle helmet wearing became mandatory in the State of Victoria, and helmet wearing is now required in all Australian states and in many jurisdictions throughout the world. British Columbia is to be commended for having the courage to take this important step in protecting its cyclists. However, although global data are not readily available, there are probably several million cyclists throughout the world in countries with varying levels of motorization, who are not wearing a helmet. This means that several tens of thousands of cyclists sustain head injuries in crashes each year.

The quoted $85 \%$ reduction in risk of head injuries and $88 \%$ for brain injuries, should be regarded as upper limits for helmets. Somewhat lower, but still substantial reductions have been found in other studies. In Melbourne, McDermott et al found 39\% reduction in head injuries in riders wearing helmets meeting the Australian standard. ${ }^{1}$ When certain casualties in the data of Thompson et al were reassigned to match the classification used in Melbourne, the Seattle reduction was $61 \%{ }^{2}$ In Cambridge, England, from a series in which about one quarter of cases involved a car, Maimaris et al obtained data from which an injury reduction of $67 \%$ can be derived. ${ }^{3}$ There are several other studies which show reductions in the same range.

While there is a need to improve further the protective performance of helmets, it is clear that thousands of head injuries could be prevented world wide by increasing wearing rates of existing helmets now. For example, in Victoria in 1983 about $5 \%$ of children under 12 years riding to school were wearing a helmet, and for 12-17 year olds the figure was less than $2 \%$. The wearing rate for adults commuting was $26 \%$, although much less in recreational cycling. After seven years of promotion, together with a $\$ 10$ rebate scheme for purchase of approved helmets, these wearing rates had risen to $77 \%, 18 \%$, and $46 \%$, respectively. The introduction of the mandatory wearing law increased the under 12 wearing rate to $92 \%$ and more than doubled the other two rates. Using statewide insurance claims for cyclists killed or admitted to hospital involved in motor vehicle related crashes, we found that the percentage with a head injury dropped from $52 \%$ in $1981 / 82$ to $35 \%$ in $1989 / 90$ as helmet wearing increased. There was a further drop to $25 \%$ in the first year after the mandatory wearing law was introduced. ${ }^{4}$

The table shows the expected annual savings by helmet wearing in a community which has 1000 cyclist head injuries per annum (assuming other factors remain unchanged). It can be seen

Expected annual savings by helmet wearing

\begin{tabular}{llllll}
\hline \multirow{3}{*}{ Helmet effectiveness } & $5^{\circ}{ }_{o}$ & $10^{\circ}{ }_{o}$ & $20^{\circ}{ }_{o}$ & $40^{\circ}{ }_{o}$ & $80^{\circ}{ }_{0}$ \\
\hline $40^{\circ}{ }_{0}$ & 20 & 40 & 80 & 160 & 320 \\
$80^{\circ}{ }_{0}$ & 40 & 80 & 160 & 320 & 640 \\
\hline
\end{tabular}


that, starting with a wearing rate of say $5 \%$, there is scope to increase the annual head injuries saved by eight times (from 20 to 160) through increasing the wearing rate to $40 \%$ through promotion and possibly 16 times by mandatory wearing. On the other hand, the most that can be achieved by improving helmet effectiveness from $40 \%$ to $80 \%$ is a doubling (from 20 to 40 injuries). Furthermore, upgrading helmet standards and having new helmets replace the old ones can take many years, while doubling the helmet wearing rates can be much quicker. Nevertheless, improving helmet protective performance is also important and should be done, but it should not detract from the urgent task of 'getting more helmets on heads'.

The criticisms in the Opinion of most existing standard and helmets are valid. Studies over the years have repeatedly noted inadequate protection to the forehead and sides of the head, particularly in the temporal region. However, the benefits of increased coverage need to be balanced against generating further resistance to helmet wearing. Such helmets should be available but perhaps not mandatory.

It is difficult to optimize the protective effect of the liner over the whole range of impact velocities and it has been suggested that liners commonly used at present are not effective at the low severity end of the range. To the extent that this is a problem, it could be ameliorated by the choice of liner material able to perform fairly well at velocities other than the test velocity. The recent amendment to the Canadian standard should encourage a suitable choice. A more radical change would specify an accelaration limit and a head injury criterion (HIC) limit (for example $200 \mathrm{~g}$ with HIC 800 proposed by McIntosh et al). ${ }^{5}$

In addition to designing the helmet to ensure optimum energy absorption and force distribution, it is important to provide appropriate sizes and adjustments to ensure a good fit and proper retention in use. Cyclists should be given appropriate advice on choosing and wearing a helmet, preferably at the time of purchase. We agree that specially sized helmets should be available for young children because despite advice from various authorities, they ride in traffic as well as off-road, and even younger children are carried as passengers.

According to helmet manufacturers, there would be considerable cost savings if there was a single bicycle helmet standard. As the injurious effect of forces applied to the head should be similar for all humans and the forces in a crash are likely to be similar in most countries, there is no good scientific reason why there should not be a universal helmet standard.

Such a standard would need to cater to the full range of head sizes and shapes. There may also be a need to have more than one level of protection specified to provide additional coverage of the temples and face for those who want it, and there may be a case for two levels of impact energy to cover usage where there is little chance of higher velocity impacts with motor vehicles and vice versa.

There is, therefore, an urgent need to agree on the performance criteria, if necessary after any further research required to facilitate such agreement. Eventually, the goal would be to have a single standard. The commercial, national, and other sectional interests of particular groups should not be allowed to stand in the way of preventing thousands of head injuries.

In the USA, Australia, and some countries in Europe, consumers are given advice on the safety performance of cars by make and model. Similar information about the protective period of various brands of bicycle helmets would be valuable.

Bicycle helmets, when properly worn, are a proven intervention and the injury prevention community should play its part in ensuring that they become widely used.

1 McDermott FT, Lane JC, Brazenor GA, Debney EA. The effectiveness of bicyclist helmets: a study of 1710 cases. $\mathcal{F}$ Trauma 1993; 34: 834-45.

2 Thompson RS, Rivara FP, Thompson DC. A case control study of the effectiveness of bicycle safety helmets. $N$ Engl f Med 1989; 320: $1361-7$.

3 Maimaris C, Summers CL, Browning C, Palmer CR. Injury patterns in cyclists attending an accident and emergency department: a comparison of helmet wearers and wearers. BMF 1994; 308: 1537-40.

4 Vulcan AP, Cameron MH, Heiman L. Evaluation of mandatory bicycle helmet use in Victoria, Australia. 36th Annual Proceedings of the Association for the Advancement of Automotive Medicine. Portland, Oregon, 5-7 October of Autor 1992.

5 McIntosh AS, Kalleris D, Mattern R, Svensson NL, Dowdell B. An evaluation of pedal cycle helmet performance requirements. Proceedings of 39th STAPP Car Crash Conference, Coronado, California. 8-10 November, Warrendale, PA: Society of Automotive Engineers, 1995: $111-9$ 